\title{
CIRANDAR: processo de formação acadêmico-profissional de professores em Rodas em Rede
}

\author{
CIRANDAR: process of \\ academic-professional education \\ of teachers in Networked Wheels
}

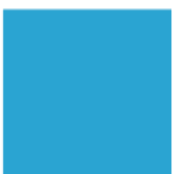

Revista

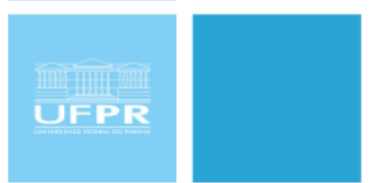

ISSN 2358.7180

\author{
Jackson Luís Martins Cacciamani ${ }^{1}$
}

\begin{abstract}
RESUMO
O CIRANDAR constitui-se num processo de formação de professores acadêmico-profissional em Rodas em Rede. O nosso coletivo de Realeza - PR constituiu-se de estudantes dos nossos cursos de Licenciatura em Química e Licenciatura em Física, bem como colegas professores da nossa Universidade Federal da Fronteira Sul - UFFS, nessa parceria com a Universidade Federal do Rio Grande - FURG - Rio Grande - RS. As rodas de conversa e de formação acerca da escritura das cartas foram essencialmente aprendentes, sendo que a partilha de conhecimentos, saberes e experiências vividas potencializou laços de afetividade entre os integrantes dessa Roda em Rede. A ideia da escritura de cartas no CIRANDAR traz à tona a importância da linguagem, especialmente, a escrita e a leitura no processo formativo de professores numa perspectiva acadêmico-profissional. Argumentamos que o CIRANDAR é um processo de formação que potencializa a auto-formação e o auto-conhecimento acerca de si e do Outro, num movimento coletivo de formação de professores em Rodas em Rede.
\end{abstract}

Palavras-chave: Formação acadêmico-profissional de professores. Escritura de cartas. Linguagem. Rodas em Rede.

\begin{abstract}
CIRANDAR is a process of education academic-professional teachers in Networked Wheels. Our Realeza - PR group consisted of students from our Chemistry and Physics Degree courses, as well as fellow professors from our Federal University of Fronteira Sul - UFFS, in this partnership with the Federal University of Rio Grande - FURG - Rio Grande - RS. The conversation and education rounds about the writing of the letters were essentially learners, and the sharing of knowledge, knowledge and lived experiences strengthened bonds of affection among the members of this Network Wheel. The idea of writing letters at CIRANDAR brings out the importance of language, especially writing and reading in the teachers' education process from an academic-professional perspective. We argue that CIRANDAR is a education process that enhances self-education and self-knowledge about oneself and the Other, in a collective movement for teacher education in Networked Wheels.
\end{abstract}

Keywords: Academic-professional education of teachers. Writing letters. Language. Network Wheels.

\footnotetext{
${ }^{1}$ Professor da Universidade Federal da Fronteira Sul - UFFS - campus Realeza - PR, Doutor em Educação em Ciências (FURG - Rio Grande - RS) - jackson.cacciamani@uffs.edu.br - https://orcid.org/0000-00017732-0262.
} 


\section{INTRODUÇÃO}

No presente texto procuro trazer as cartas escritas enquanto/como professor mediador da Roda em Rede na cidade de Realeza - PR, sendo que escrevemos e lemos três cartas orientadas pelo coletivo de organização do CIRANDAR (professora Maria do Carmo Galiazzi e professora Aline Machado Dorneles, bem como demais colegas professores que constituem esse coletivo pertencentes à Universidade Federal do Rio Grande - FURG - RS). O nosso coletivo de Realeza - PR, pertencente à Universidade Federal da Fronteira Sul - UFFS - é constituído por alguns dos nossos estudantes dos cursos de Licenciatura em Química e Licenciatura em Física, assim como colegas professores da nossa instituição - OLIVEIRA, Carmen Elizabete; EDUARDO, Andreia Florêncio; LAZAROTO, Ana Claudia; GARCIA, Ronaldo Aurélio Gimenes; VOLOSKI, Gilson Luís; VOLOSKI, Giovani Luís; VIAN, Gabriel Vinícius; SILVA, Mateus Gabriel Magedanz; ZANONI, Breno Henrique Bianco; HAGEMANN, Eduarda Carolina Scherer.

Nem todos os colegas conseguiram seguir a caminhada formativa conosco por causa de diversos episódios, bem como não poderemos esquecer que estamos vivenciando uma das crises civilizatórias mais complexas da história da humanidade que é a pandemia do Covid-19, mas reitero que esse trabalho que publicamos e publicizamos na Revista Extensão em Foco da UFPR é de autoria desse coletivo, pois sou apenas um interlocutor nesse processo.

Ainda gostaria de agradecer por essa oportunidade de participar e de vivenciar esse processo formativo do CIRANDAR que é aprendente e transformador numa perspectiva de formação acadêmico-profissional, sendo que estamos nessa Roda em Rede em processo de auto-formação e de auto-conhecimento. Por isso, a seguir partilho com a comunidade de professoras e professores as três cartas que escrevi inspiradas nas cartas tão acolhedoras que recebemos da nossa querida professora Maria do Carmo e que tiveram a intenção de catalisar e potencializar os processos de escritura das cartas nessa Roda em Rede, tais como: 


\section{PRIMEIRA CARTA:}

\section{Como venho me constituindo professor pertencente à área da Educação em Ciências no coletivo?}

Realeza, 28 de setembro de 2020.

Queridas e queridos colegas, tudo bem? Espero que estejam todas e todos bem ao receberem essa carta.

Já faz alguns dias que reservei um tempo para escrever a vocês no sentido de acolhê-las e acolhê-los nesse nosso processo de formação de professores em Rodas em Rede que é o Cirandar: Rodas de Investigação desde a Escola - mas só hoje consegui terminar de escrever.

Acredito que estamos vivenciando um momento complexo e inusitado com essa pandemia do Covid-19, pois é uma situação tão entristecedora, principalmente, no Brasil.

Contudo, que nunca percamos a nossa esperança freireana no sentido pleno da palavra pois como tudo na vida é um processo e, portanto, tem um começo, meio e fim. E, por aí decido me apresentar aos colegas. Aproveito a belezura do início da primavera e o encantamento que tenho com a natureza desde criança, especialmente, com as flores no sentido de escolher o modo que pretendo me apresentar, ou seja, valorizando as presenças na minha história de vida pessoal e profissional para além das ausências.

E, certamente, na minha compreensão de mundo a primavera é uma das épocas mais belíssimas do ano, pois sinaliza o recomeço, o reinventar, a reconstrução [...] de tudo que poderemos categorizar como formas de vida. E, sermos professoras e professores é um estilo de vida que escolhemos por profissão!

As pessoas que me conhecem de forma amiúde têm ideia de que sou encantando com a nossa profissão, uma vez que enquanto professor me percebo, me reconheço e me entendo incompleto, inconcluso e inacabado em cada momento. E a oportunidade de aprender coletivamente com os nossos colegas e os nossos estudantes me instiga a aprender a aprender, especialmente, ancorados nas linguagens diversas.

A minha história de vida como professor começa ainda no Ensino Médio (São Borja - RS) quando escolhi cursar Magistério e, certamente, essa escolha transformou a 
minha vida. Gratidão a minha mãe Sirley e meu pai Agostinho por me apoiarem nessa decisão!

Depois escolhi na graduação a Licenciatura em Ciências (FURG - Rio Grande RS) e por aí segui até hoje num caminho que me proporcionou incertezas, inquietudes, alegrias e realizações assim como é a complexidade da vida. Esse sonho de cursar o Ensino Superior somente se transformou em realidade por causa do acolhimento dos meus familiares tanto em São Borja - RS quanto em Rio Grande - RS. Gratidão eterna que nunca conseguirei expressar em palavras!

A minha primeira experiência profissional ocorreu no Colégio Estadual Bibiano de Almeida (Rio Grande - RS) onde trabalhei por dez anos com o Ensino Médio e a Educação de Jovens e Adultos (EJA). Nessa escola me constituí professor na interação com os meus colegas professores e demais servidores da escola, bem como com os nossos estudantes. E, na interação sempre com os meus professores inesquecíveis na universidade. Gratidão! Principalmente, por laços de afetividade e de amizade que transcendem o espaço e o tempo!

Enquanto professor no Ensino Superior me compreendo em processo de formação permanente assim como sempre me compreendi na escola da Educação Básica, sendo que a linguagem na formação de professores me encanta, me constitui e me movimenta a seguir em frente apostando sempre nessa interação entre a escola, a universidade e a comunidade.

Gratidão aos meus professores inesquecíveis (Maria do Carmo, Moacir, Roque (in memoriam)) por todo o acolhimento, afetividade, aprendizagens partilhadas, bem como por me ensinarem conteúdos humanos, éticos e estéticos! Maria do Carmo é a minha eterna orientadora que desde a graduação me proporcionou espaços e tempos na formação de professores! Os laços de amizade construídos ao longo desses anos são essencialmente importantes na minha história de vida! Eu poderia elencar também alguns outros professores que me constituíam ao longo da minha caminhada escolar. Pois é nessa interação dialógica e de afetividade que nos constituímos "gente" humana no sentido pleno da palavra.

Sou grato aos meus familiares e amigos que sempre estiveram comigo em cada momento para além das distâncias geográficas e que não permitem que "os butiás caiam do meu bolso" nem tampouco que eu fique "chorando às pitangas" por aí [...] pois são 
laços de afetividade e de amizade que transcendem a explicação das palavras. Aos meus colegas da escola e da universidade [...] gratidão! Pois juntos aprendemos em cada momento nesse coletivo, bem como aos nossos estudantes - sentido de tudo nesse processo de aprender e de ensinar! Nessa interação construímos laços de afetividade que produzem sentidos nessa caminhada formativa!

Acredito que sou uma pessoa que gosto da simplicidade, da genuinidade, da sinceridade, da leveza nas interações e acredito essencialmente no poder do amor, do afeto, do respeito, da alteridade, etc. Por isso, sigo esperançoso em acreditar num mundo mais humano, estético e ético - especialmente, quando penso nos meus filhos (a essencialidade da produção de sentidos na minha vida - amorosidade que não se expressa em palavras em nenhum idioma), bem como em relação aos nossos estudantes. Que as novas gerações tenham o privilégio de vivenciar um mundo mais humanizado!

Nessa experiência complexa e encantadora da vida [...] outras pessoas que sequer conheço pessoalmente me constituem por sua obra musical, artística e literária, por exemplo, Adriana Calcanhoto, Gilberto Gil, Pedro Weinghartner, Tarsila do Amaral, Mário Quintana e Clarice Lispector, dentre tantas outras que ao longo desses anos de vida me proporcionaram sonhar, idealizar, esperançar, etc.

Por isso desejo a vocês queridas e queridos colegas que a primavera nos proporcione alento, alegria e esperança de seguirmos em frente. E que ainda sigamos acreditando na formação de professores, especialmente, nessa interação entre a escola, a universidade e a comunidade!

O recorte abaixo é de uma obra de Cora Coralina (me constituí por sua singularidade e simplicidade) e diz de algum modo o que gostaria de expressar nessa carta a vocês! Sejam muito bem-vindas e bem-vindos ao nosso Cirandar! Gratidão por estarmos todas e todos juntos nesse processo de formação que é encantador por sua essência! 


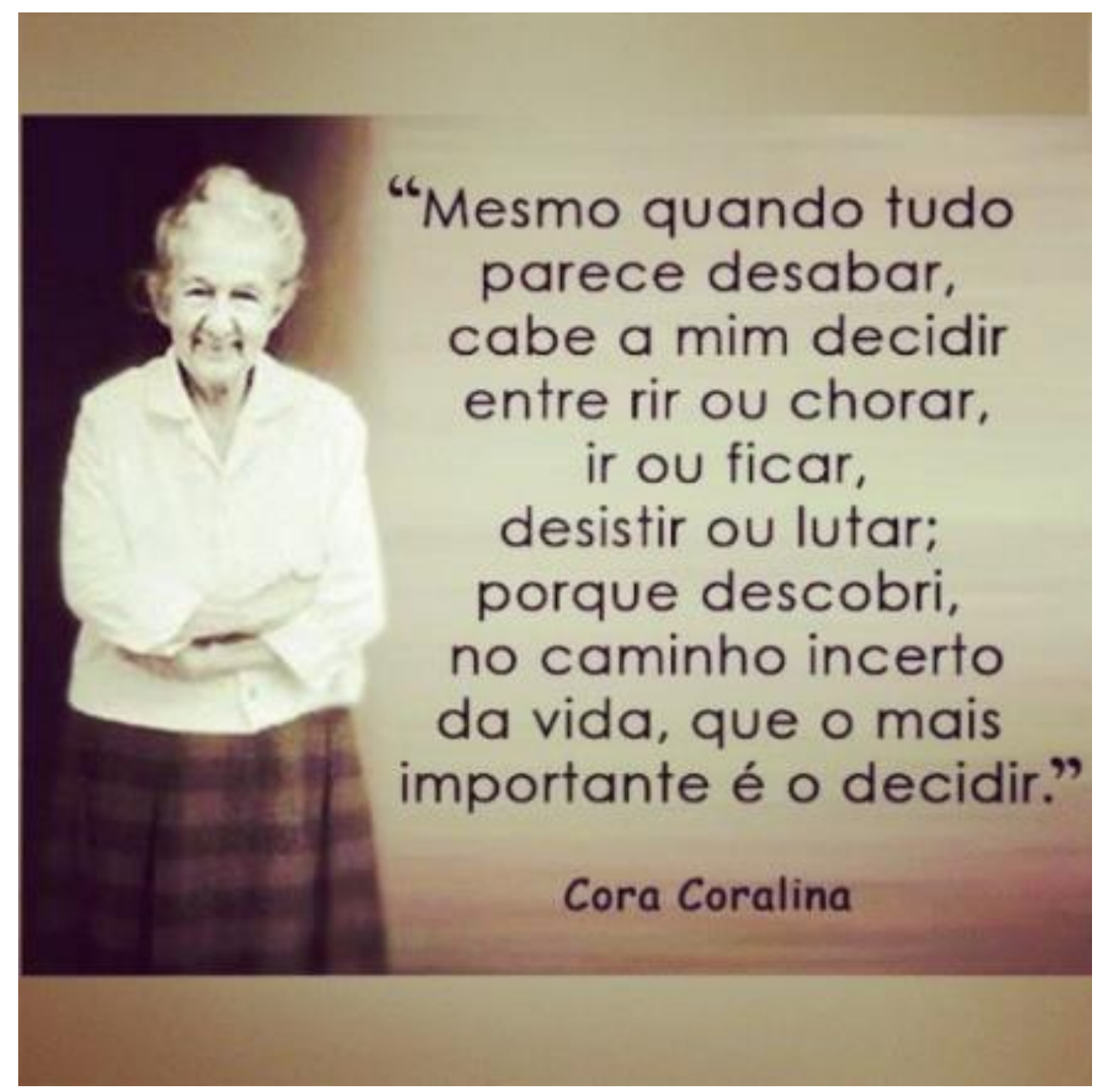

FONTE: [www. google.com/imagens] acessado em 23 de maio de 2021.

Um afetuoso abraço

Jackson

$* * *$

\section{SEGUNDA CARTA:}

O que emerge das minhas experiências vividas no coletivo que pretendo compreender com mais complexidade?

Realeza, 17 de novembro de 2020.

Boa tarde queridas e queridos colegas professores Ana Cláudia, Eduarda, Mateus, Giovani, Gabriel e Breno, tudo bem? Espero que esteja tudo bem com vocês.

Quando pensei em escrever essa carta procurei rememorar os episódios diversos que vivenciei ao longo dessa pandemia que na minha opinião é uma das crises 
civilizatórias mais complexas e entristecedoras dos últimos tempos a nível mundial, sendo que no Brasil estamos num barco à deriva diante do modo que os governantes veem conduzindo os encaminhamentos na área da educação, saúde e meio ambiente, principalmente. Contudo, de modo algum poderemos deixar “os butiás caírem do bolso”!

Desde o começo da pandemia organizei uma roda de conversa em que Ana Cláudia, Eduarda e Mateus estiveram presentes, por exemplo, ao longo do tempo via um grupo no Facebook e depois conversas semanais via Hangout do "gmail". A intenção dessa roda de conversa era interagirmos acerca da relação entre Ciências, Arte e Cultura no enfrentamento da pandemia do Covid-19. Mas [...] para além disso a ideia era partilharmos experiências acerca desse momento tão complexo e desafiador que estamos vivendo, ou seja, estarmos juntos nesse momento (eu enquanto professor em formação continuada e os nossos estudantes em formação inicial, ou seja, todos em formação acadêmico-profissional como nos ensina Diniz-Pereira). E, obviamente, as nossas rodas de conversa do nosso Grupo de Pesquisa em Educação em Ciências Naturais (GPECieN) nas sextas-feiras, quinzenalmente, sempre tão acolhedoras, aprendentes e esperançosas.

Gratidão por vocês todas e todos partilharem comigo esses espaços e tempos, pois sempre são carregados de afetividade, de diálogo e de acolhimento! Penso que isso nos proporcionou entender que embora a distância estivemos sempre presentes nesse momento na vida uns dos outros. Isso nos faz pensar que precisamos inventar outros modos de interagirmos no sentido de nos preservarmos e preservarmos as demais pessoas que convivem conosco e que são importantes em nossas vidas por causa dessa pandemia do Covid-19.

Em meados de setembro começamos o nosso semestre de modo online ou remoto, sendo que nesse semestre ministro quatro componentes curriculares (CCRs): [1] Iniciação à docência em Química; [2] Estágio Curricular Supervisionado I - Ensino Fundamental; [3] Projeto de Pesquisa em Química II - Ensino Médio e [4] Tecnologia e Sociedade. Contudo, optei por suspender uma delas (Tecnologia e Sociedade) por ser um momento novo que estamos aprendendo juntos a sermos professoras e professores de modo online ou remoto (não tenho clareza do melhor conteúdo conceitual sobre isso), embora, sendo um dos CCRs que sou encantado com proposta.

Por conseguinte, nas terças, quartas e sextas-feiras eu tenho as rodas de conversa dos CCRs com os nossos estudantes. Normalmente, nos finais de semana procuro me 
organizar quanto ao planejamento, estudo e pesquisa acerca da proposta da aula em si. Pois, especialmente, nesse outro jeito que encontramos é uma interação diferente e no meu ponto de vista precisa ser, sim, uma roda de conversa em que vocês que são os nossos estudantes estejam num espaço-tempo de acolhimento, de partilha, de escuta atenta, de diálogo e afetividade, pois isso na minha compreensão potencializa o processo de aprender coletivamente. Num desses CCRs eu tenho trabalhado coletivamente com a professora Glessyan (nossa colega pertencente a área da Educação Química) que agradeço muito por todo o apoio e parceria nesse processo de formação dos estágios.

Penso que embora o modo online ou remoto (ou qualquer outro termo que adotarmos) existem limites e potencialidades assim como no presencial. Certamente, para além da nossa apropriação das ferramentas tecnológicas existem outros episódios que transcendem o processo de aprender e de ensinar em si dos CCRs. Por outro lado, esse momento de partilha, de diálogo e de aprendizagem coletiva é bastante especial! Obviamente, que não estou sendo ingênuo a ponto de pensar que conseguimos resolver o problema desse modo, mas estou procurando fazer aquilo que acredito, ou seja, apostar nas presenças para além das ausências.

No processo dos estágios vem ocorrendo episódios muito interessantes de partilharmos esse momento com os colegas professores das escolas e assim aprendermos coletivamente acerca desse enfrentamento da pandemia do Covid-19. Pois se por cá consideramos o processo complicado por lá a situação é bem complexa, pois estamos lidando com crianças e adolescentes que merecem olhares atentos no que tange ao processo de aprender e de ensinar. Obviamente, que os nossos estudantes da universidade merecem de modo igual cuidados no processo de aprender e de ensinar, mas por tese já adquiriram de algum modo mais autonomia.

Quando digo "cuidados no processo de aprender e de ensinar" refiro-me a uma interação baseada no afeto, no diálogo, na coletividade, na alteridade, etc. Pois tanto lá quanto cá precisamos encontrar um caminho de transformarmos esse momento tão complexo num momento de humanização numa perspectiva de Educação Estética. A estética das interações humanas que transcende qualquer ideia de escolaridade, de nível de ensino, de espaço e de tempo. Reitero que precisamos todos os dias das nossas vidas fazer o exercício de humanização e assim nos humanizarmos coletivamente. 
Nesse ínterim muitas vidas foram ceifadas por esse vírus que assim como os microrganismos de modo geral têm uma grande capacidade de adaptação e de modificação genética, sendo muito mais complexa a sua cura. O ano de 2020 sempre será lembrado por essa tragédia que assolou a humanidade sem escolher idade, gênero, etnia, classe social, etc. Ou seja, fomos interpelados por um microrganismo capaz de ocasionar uma doença sistêmica atingindo assim diversos órgãos e, obviamente, as pessoas que pertencem ao grupo de risco por diversas enfermidades encontram-se mais fragilizadas diante de tudo isso.

Por isso, eu tenho pensado muito acerca dos "conteúdos" escolares tanto na escola da Educação Básica quanto na Universidade. Pois dentro da área da Educação em Ciências, especialmente, Educação Química essa é uma discussão recorrente desde muito tempo. Contudo, nunca antes vivenciamos uma pandemia nesse sentido. Então, penso que os conteúdos tanto lá quando cá precisam pertencer ao campo da humanidade. Pois gosto de pensar que embora a complexidade e tristeza desse momento ainda temos a oportunidade de evoluirmos como seres humanos Homo sapiens sapiens.

As minhas inquietudes, incertezas e inseguranças são diversas, por isso, partilho com o nosso coletivo do Cirandar. Que conteúdos são esses que precisamos abordar nos espaços educativos num momento em que o mundo é interpelado por uma pandemia que certamente é uma das maiores crises civilizatórias da sociedade contemporânea? Qual é o papel da escola da Educação Básica e da Universidade num momento tão complexo? Por que precisamos de uma pandemia para percebermos a nossa fragilidade como seres humanos? Por que embora a pandemia muitas pessoas ainda ignoram e desconsideram a desigualdade social, histórica, cultural, econômica [...] no Brasil e no mundo? Quando realmente seremos conscientes sócio-histórico-ambientalmente no sentido de transformarmos as nossas ações acerca do ambiente? Por que precisamos do capitalismo como sistema hegemônico no mundo? Como professoras e professores o que poderemos fazer no sentido de esperançar freireanamente diante de um momento tão complexo? O que poderemos aprender com essa pandemia? E ainda o que nos permitimos aprender com a pandemia? Etc.

Enfim, acredito que estamos diante de um momento tão complexo e aprendente de outros modos de sermos professoras e professores, ou melhor, de sermos seres humanos. Certamente, isso nos proporciona insegurança e incerteza, mas o processo de aprender e de ensinar é pautado nesse movimento da provisoriedade, da incerteza, da 
insegurança ... pois é isso que nos movimenta a aprender a aprender numa produção de sentidos.

Ana Cláudia, Eduarda, Mateus, Giovani, Gabriel e Breno que nunca percamos a nossa esperança freireana nem o encantamento com a docência embora os episódios desafiadores que nos interpelam, pois esses podem se constituir em processos de autoformação e de auto-conhecimento essencialmente produtores de sentidos na nossa história de formação tanto pessoal quanto profissional.

Por isso, partilho com vocês essa música de Almir Sater e Renato Teixeira que é uma preciosidade estética. E assim encerro essa carta nesse momento, bem como agradeço a leitura e a escuta atenta de vocês, pois a intenção era partilhar esse momento pandêmico com vocês e assim fazermos um exercício de alteridade a respeito desse momento que é tão complicado [...] bem como reiterar o argumento de que tenhamos esperança de que isso tudo vai ser sublimado e que sigamos acreditando na potencialidade da nossa transformação humana.

Um afetuoso abraço

Jackson

TOCANDO EM FRENTE (Almir Sater e Renato Teixeira)

\author{
Ando devagar \\ Porque já tive pressa \\ E levo esse sorriso \\ Porque já chorei demais. \\ Hoje me sinto mais forte \\ Mais feliz, quem sabe \\ Só levo a certeza \\ De que muito pouco sei \\ Ou nada sei. \\ Conhecer as manhas \\ E as manhãs \\ O sabor das massas \\ E das maçãs. \\ É preciso amor \\ Pra poder pulsar \\ É preciso paz pra poder sorrir \\ É preciso a chuva para florir.
}


Penso que cumprir a vida

Seja simplesmente

Compreender a marcha

$\mathrm{E}$ ir tocando em frente.

Como um velho boiadeiro

Levando a boiada

Eu vou tocando os dias

Pela longa estrada, eu vou

Estrada eu sou.

Conhecer as manhas

$\mathrm{E}$ as manhãs

O sabor das massas

E das maçãs.

É preciso amor

Pra poder pulsar

É preciso paz pra poder sorrir

É preciso a chuva para florir.

Todo mundo ama um dia

Todo mundo chora

Um dia a gente chega

E no outro vai embora.

Cada um de nós compõe a sua história

Cada ser em si

Carrega o dom de ser capaz

E ser feliz.

Conhecer as manhas

$\mathrm{E}$ as manhãs

O sabor das massas

E das maçãs.

É preciso amor

Pra poder pulsar

É preciso paz pra poder sorrir

É preciso a chuva para florir.

Ando devagar

Porque já tive pressa

E levo esse sorriso

Porque já chorei demais.

Cada um de nós compõe a sua história

Cada ser em si

Carrega o dom de ser capaz

E ser feliz.

$* * *$ 


\section{TERCEIRA CARTA:}

\section{Como cheguei no coletivo?}

Realeza, 04 de abril de 2021.

Queridas e queridos colegas, tudo bem? Espero que estejam todas e todos bem ao receberem essa carta, principalmente, com saúde e esperança de que tenhamos momentos mais tranquilos diante dessa pandemia.

Que todas as brasileiras e brasileiros tenham acesso à vacinação contra o Covid19, bem como nos demais países do mundo! E, especialmente, que esse momento tão complexo e triste na história da humanidade nos últimos tempos seja sublimado e assim consigamos reconstruir e reinventar as nossas vidas após a pandemia.

Acredito que estamos vivenciando um momento complexo e inusitado, pois é uma situação tão entristecedora, principalmente, no Brasil. Contudo, gosto de pensar que posteriormente a esse momento teremos novos caminhos num sentido de um processo civilizatório mais estético, ético e humanizado!

Quando iniciamos esse processo do Cirandar começava a primavera e agora estamos no outono (estação que possui seus encantamentos por causa das temperaturas mais amenas, da diversidade de cores das folhas e das flores das árvores caindo no chão, do vento soprando novos horizontes, dos dias com menos horas de Sol, das noites mais estreladas, dentre outras tantas características que me encantam, emocionam e potencializam acreditar no esperançar como sempre nos ensina Freire, especialmente, em espaços e tempos mais justos, tranquilos e acolhedores).

As pessoas que me conhecem de forma amiúde têm ideia de que sou encantado com a nossa profissão, uma vez que enquanto professor me percebo, me reconheço e me entendo incompleto, inconcluso e inacabado em cada momento como nos ensina Freire. E a oportunidade de aprender coletivamente com os nossos colegas professores e os nossos estudantes me instiga a aprender a aprender, especialmente, ancorados nas linguagens diversas que nos constituem (a escrita, a leitura, a fala, a música, o cinema, a literatura, a arte, enfim, as diversas formas que poderemos aprender a aprender a compreender a boniteza do mundo). 
Desde o começo da pandemia organizei uma roda de conversa em que Helena e Pedro estiveram presentes, por exemplo, ao longo do tempo via um grupo no Facebook e depois conversas semanais via Hangout do "gmail". A intenção dessa roda de conversa era interagirmos acerca da relação entre Ciências, Arte e Cultura no enfrentamento da pandemia do Covid-19. Mas [...] para além disso a ideia era partilharmos experiências acerca desse momento tão complexo e desafiador que estamos vivendo, ou seja, estarmos juntos nesse momento apoiando uns aos outros, e, acima de tudo percebendo que embora a situação em si não estamos sozinhos. E, obviamente, as nossas rodas de conversa do nosso Grupo de Pesquisa em Educação em Ciências Naturais (GPECieN) nas sextasfeiras, quinzenalmente, sempre tão acolhedoras, aprendentes e esperançosas potencializam esse esperançar.

Gratidão aos nossos colegas professores e estudantes por partilharem comigo esses espaços e tempos, pois sempre são carregados de afetividade, de diálogo e de acolhimento! Penso que isso nos proporcionou entender que embora a distância estivemos sempre presentes nesse momento na vida uns dos outros. Isso nos faz pensar que precisamos inventar outros modos de interagirmos no sentido de nos preservarmos e preservarmos as demais pessoas que convivem conosco e que são importantes em nossas vidas por causa dessa pandemia do Covid-19.

As rodas de conversa do Cirandar se constituíram ao longo desse tempo outro momento de interação, de formação e de partilha de conhecimentos e saberes acerca da nossa constituição como professoras e professores. Gratidão a professora Maria do Carmo e a professora Aline por essa oportunidade de estarmos todos juntos nessa Roda em Rede, assim como aos colegas pertencentes aos diversos espaços e tempos do Cirandar [...] por estarmos coletivamente partilhando experiências vividas acerca da nossa constituição docente, bem como afetos e acolhimentos.

Em meados de setembro começamos o nosso semestre de modo online ou remoto, sendo outro momento de partilha, de diálogo e de aprendizagem coletiva com os nossos estudantes! Obviamente, que não estou sendo ingênuo a ponto de pensar que conseguimos resolver o problema desse modo, mas estou procurando fazer aquilo que acredito, ou seja, apostar nas presenças para além das ausências. E ao mesmo tempo enfrentar os meus limites tecnológicos e assim aprender coletivamente com os meus colegas professores e nossos estudantes - professores em formação em Educação em Ciências, especialmente, Educação Química. 
No processo dos estágios vem ocorrendo episódios muito interessantes de partilharmos esse momento com os colegas professores das escolas e assim aprendermos coletivamente acerca desse enfrentamento da pandemia do Covid-19. A situação em que estamos inseridos nesse momento diante da perspectiva do processo de aprender e de ensinar online ou remoto é complexa tanto na escola da Educação Básica quanto na Universidade, pois a nossa historicidade de formação é pautada no presencial. Embora, os nossos estudantes tenham hoje acesso às Tecnologias da Informação e Comunicação (TICs) [...] o processo de aprender e de ensinar não se resume nisso, uma vez que envolve outras tantas questões que no presencial já são complexas. Por isso, precisamos pensar noutros conteúdos para além dos conceituais. Aliás, isso não somente no momento de uma pandemia, mas me parece que nesse momento que estamos vivendo trouxe à tona limites e potencialidades que já enfrentamos no presencial, mas, agora, de outros modos nesse espaço e tempo.

As nossas interações em sala de aula com os nossos estudantes quando pautadas no afeto, no diálogo, na coletividade e na alteridade, por exemplo, produzem sentidos nas histórias de vida tanto nossa quanto deles. Pois tanto na escola da Educação Básica quanto na Universidade precisamos encontrar um caminho de transformarmos esse momento tão complexo num momento de humanização numa perspectiva de Educação Humanizadora.

O ano de 2020 sempre será lembrado por esse episódio que assolou a humanidade sem escolher idade, gênero, etnia, classe social, etc. Ou seja, fomos interpelados por um microrganismo capaz de ocasionar uma doença sistêmica atingindo assim diversos órgãos e, obviamente, as pessoas que pertencem ao grupo de risco por diversas enfermidades encontram-se mais fragilizadas diante de tudo isso. E [...] nunca estivemos no mesmo barco, não! Ou seja, as pessoas mais carentes nesse país que sequer tem condição de uma vida digna são bem mais atingidas por tudo isso que estamos vivendo, principalmente, no que diz respeito ao desemprego e, por conseguinte à fome.

Por isso, Helena, Pedro, Marina, Lucas, Jean e Bruno [...] eu tenho pensado muito acerca dos "conteúdos" escolares tanto na escola da Educação Básica quanto na Universidade. Nunca antes vivenciamos uma pandemia nesse sentido. Então, penso que os conteúdos tanto lá quando cá precisam pertencer ao campo da humanidade. Pois gosto de pensar que embora a complexidade e tristeza desse momento ainda temos a oportunidade de evoluirmos como seres humanos. 
Souza (2011) problematiza acerca dos conteúdos na sua tese de doutoramento quando pergunta: “Conteúdos: Mas que conteúdos?”. Por isso, poderíamos pensar que a sala de aula pautada na pesquisa de acordo com o argumento de Galiazzi (2003), especialmente, nesse momento da pandemia poderia ser organizada com a preocupação em outros conteúdos para além dos conceituais, por exemplo, atitudinais, procedimentais, sociais, culturais, morais, éticos, políticos, religiosos e a linguagem (escrita, leitura, oralidade, música, cinema, literatura, fotografia, arte, etc), ou seja, conteúdos que não se encontram categorizados apenas dentro de uma área do conhecimento mas pertencem a uma perspectiva de Educação Humanizadora e Estética.

Por isso, as minhas inquietudes, incertezas e inseguranças são diversas nesse espaço-tempo da pandemia acerca da minha constituição como professor pertencente a área da Educação em Ciências, sendo que partilho com o coletivo de colegas professores do Cirandar. O Cirandar é uma proposta de formação de professores acadêmicoprofissional (Diniz-Pereira, 2008), ou seja, a interação entre a escola, a universidade e a comunidade é potencialmente formativa, aprendente e transformadora. Então, elenco algumas das minhas inquietudes com o nosso coletivo do Cirandar, tais como: Que conteúdos são esses que precisamos abordar nos espaços educativos num momento em que o mundo é interpelado por uma pandemia que certamente é uma das maiores crises civilizatórias da sociedade contemporânea? Qual é o papel da escola da Educação Básica e da Universidade num momento tão complexo? Por que precisamos de uma pandemia para percebermos a nossa fragilidade como seres humanos? Por que embora a pandemia muitas pessoas ainda ignoram e desconsideram a desigualdade social, histórica, cultural, econômica [...] no Brasil e no mundo? Quando realmente seremos conscientes sóciohistórico-ambientalmente no sentido de transformarmos as nossas ações acerca do ambiente? Por que precisamos do capitalismo como sistema hegemônico no mundo? Como professoras e professores o que poderemos fazer no sentido de esperançar freireanamente diante de um momento tão complexo? O que poderemos aprender com essa pandemia? E ainda o que nos permitimos aprender com a pandemia? Etc. Enfim, acredito que estamos diante de um momento tão complexo e aprendente de outros modos de sermos professoras e professores. Certamente, isso nos proporciona insegurança e incerteza, mas o processo de aprender e de ensinar é pautado nesse movimento da provisoriedade, da incerteza, da insegurança [...] pois é isso que nos movimenta a aprender a aprender numa produção de sentidos. 
Quando penso na sala de aula tanto da escola quando da universidade lembro da riqueza das interações humanas, ou seja, a interação entre professores e estudantes que no momento que conseguimos estabelecer uma relação de confiança, de afetividade, de respeito e de coletividade potencializamos processos de aprender e de ensinar mais intensos, densos e produtores de sentidos num espaço-tempo em que professores e estudantes aprendem juntos a serem melhores como seres humanos.

Por isso, o processo de formação do Cirandar representa um movimento de autoformação e de auto-conhecimento em que coletivamente aprendemos a sermos professoras e professores que procuram entender de modo crítico, reflexivo e teorizado acerca das suas incertezas, incompletudes e inseguranças quanto ao processo formativo de si mesmas e mesmos, bem como de suas estudantes e de seus estudantes, pois coletivamente aprendem a importância de cada uma e cada um no seu processo formativo.

O Cirandar é um espaço-tempo de formação numa perspectiva estética e humanizadora, pois no momento que partilhamos experiências vividas, conhecimentos e saberes que nos constituem como seres humanos e, portanto, profissionais da Educação que escrevem, leem e dialogam acerca da sua identidade e constituição docente estamos em processo de formação acadêmico-profissional. O Cirandar se constitui por Rodas em Rede de professoras e professores que reconhecem e compreendem que a nossa constituição ocorre de modo coletivo, dialógico e afetivo.

Helena, Pedro, Marina, Lucas, Jean e Bruno que nunca percamos a nossa esperança freireana nem o encantamento com a docência embora os episódios desafiadores que nos interpelam, pois esses podem se constituir em processos de autoformação e de auto-conhecimento essencialmente produtores de sentidos na nossa história de formação tanto pessoal quanto profissional.

Agradeço às colegas e aos colegas pertencentes ao espaço-tempo do Cirandar! Espaços e tempos nas nossas Rodas de Realeza (Ronaldo, Gilson, Carmen, Andréia, Ana Claudia, Mateus, Giovani, Gabriel, Eduarda e Breno) - pena que nem todas e todos conseguiram seguir essa caminhada formativa conosco, obviamente, por situações diversas [...] mas sejam sempre muito bem vindas e bem vindos na nossa Roda de Realeza, bem como agradeço a cada uma e cada um dos colegas por cada momento de partilha, de diálogo e de esperançar coletivamente), nas nossas Rodas dos Mediadores (Maria, Aline, Rafaela, Anahy, Thaís, Márcia, Diana, Vivian, Elena, Ida, Sandra, Mara, 
Charles, Patrícia, Robson, Marcus, entre tantas e tantos outros colegas professores que fizeram parte dessas Rodas em Rede) grato por cada momento de partilha, de diálogo e de sonhar para além desse momento tão complexo, aos colegas professores interlocutores por meio das cartas (Daniela, Greice e José Vicente) que partilharam suas experiências vividas conosco e à colega professora (Anahy) por essa belíssima carta tão dialógica e afetuosa que me fez repensar e reconstruir novos significados acerca desse momento tão complexo que estamos vivendo. Muito obrigado por essa partilha de experiências vividas, bem como por teu acolhimento!

\author{
Pedra filosofal [Antônio Gedeão] \\ Eles não sabem que o sonho \\ é uma constante da vida \\ tão concreta e definida \\ como outra coisa qualquer, \\ como esta pedra cinzenta \\ em que me sento e descanso, \\ como este ribeiro manso \\ em serenos sobressaltos, \\ como estes pinheiros altos \\ que em verde e oiro se agitam, \\ como estas aves que gritam \\ em bebedeiras de azul. \\ Eles não sabem que o sonho \\ é vinho, é espuma, é fermento, \\ bichinho álacre e sedento, \\ de focinho pontiagudo, \\ que fossa através de tudo \\ num perpétuo movimento. \\ Eles não sabem que o sonho
}


é tela, é cor, é pincel, base, fuste, capitel, arco em ogiva, vitral, pináculo de catedral, contraponto, sinfonia, máscara grega, magia, que é retorta de alquimista, mapa do mundo distante, rosa-dos-ventos, Infante, caravela quinhentista, que é Cabo da Boa Esperança, ouro, canela, marfim, florete de espadachim, bastidor, passo de dança,

Colombina e Arlequim, passarola voadora, pára-raios, locomotiva, barco de proa festiva, alto-forno, geradora, cisão do átomo, radar, ultra-som, televisão, desembarque em foguetão na superfície lunar.

Eles não sabem, nem sonham, que o sonho comanda a vida.

Que sempre que um homem sonha o mundo pula e avança como bola colorida 
entre as mãos de uma criança.

Que nunca deixemos de sonhar e de acreditar num mundo mais justo, humano, estético, ético e cheio de amorosidade!

Um afetuoso abraço

Jackson

\section{AGRADECIMENTOS}

Agradecemos ao coletivo dessa proposta de formação de professores do CIRANDAR: Rodas de Investigação desde a Escola da Universidade Federal do Rio Grande - FURG - Rio Grande - RS, especialmente, a professora Aline Machado Dorneles e a professora Maria do Carmo Galiazzi (coordenadoras desse projeto de extensão na formação acadêmico-profissional de professores).

\section{REFERÊNCIAS BIBLIOGRÁFICAS}

DINIZ-PEREIRA, Júlio Emílio. A formação acadêmico-profissional: Compartilhando responsabilidades entre as universidades e escolas. Trajetórias e processos de ensinar e aprender: didática e formação de professores. In: XIV ENDIPE, 2008, Pontifícia Universidade Católica do Rio Grande do Sul (PUCRS), Porto Alegre. Anais... Porto Alegre, 2008.

GALIAZZI, Maria do Carmo. Educar pela Pesquisa - ambiente de formação de professores de Ciências. Ijuí: Editora da Unijuí, 2003. 288p.

SOUZA, Moacir Langoni de. Histórias de professores de Química em Rodas de formação em Rede: Colcha de Retalhos Tecida em Partilhas (d)e Narrativas. Ijuí: Editora da Unijuí, 2011.

Recebido em: 31 de maio de 2021. Aceito em: 26 de julho de 2021. 